\title{
A variação denominativa no discurso especializado do universo da cana-de-açúcar: a pertinência de dados orais na pesquisa terminológica
}

\section{The denominative variation in specialized discourse of sugarcane: the pertinence of oral data to terminological research}

\author{
Luís Henrique Serra ${ }^{*}$ \\ Universidade Federal do Maranhão \\ Codó, Maranhão, Brasil
}

\begin{abstract}
Resumo: Este artigo relata uma pesquisa sobre a variação denominativa no discurso especializado do agrônomo que trabalha com a cana-de-açúcar. O estudo mostra a relevância do canal comunicativo (oralidade ou escrita) na variação encontrada no discurso do agrônomo em diferentes contextos especializados. Parte-se das discussões apresentadas pela Terminologia Descritivista e entende-se a variação como algo natural dentro dos estudos terminológicos. O corpus utilizado é constituído de dados orais e escritos produzidos por especialistas em cana-de-açúcar em diferentes circunstâncias de comunicação especializada. Os dados mostram que a oralidade e a escrita são relevantes para a variação encontrada.
\end{abstract}

Palavras-chave: Variação denominativa. Fatores de variação terminológica. Oralidade e escrita. Cana-deaçúcar.

\begin{abstract}
This paper reports a research about the denominative variation in the specialized discourse of the agronomist who works with sugarcane. The study shows the relevance of the communicative channel (oral or written) in the variation found in agronomist discourse in different specialized contexts. It starts from the discussions presented by Descriptive Terminology and it is understood the variation as something natural within the terminological studies. The corpus used is composed by oral and written data produced by specialists in sugarcane in different circumstances of specialized communication. The data show that orality and writing are relevant to the variation founded.
\end{abstract}

Keywords: Denominative variation. Factors of terminological variation. Orality and written. Sugarcane.

\section{INTRODUÇÃO}

Esta é a parte de uma pesquisa sobre a variação denominativa do universo da canade-açúcar em que buscamos observar as causas que condicionam a variação terminológica no discurso especializado do universo canavieiro (SERRA, 2019). A pesquisa elencou um conjunto de fatores considerados como funcionais para observar qual deles é o mais

*Professor de Linguística - Universidade Federal do Maranbão, Codó, Maranhão, Brasil. E-mail: luis.ufma@gmail.com. 
relevante para o quadro da variação denominativa encontrado nos dados desse universo. Dentre os fatores selecionados, o da materialização, ou seja, o canal comunicativo escolhido pelo especialista tende a ser um dos fatores relevantes para essa variação. A partir disso, observamos um fator que é pouco explorado pela pesquisa terminológica como um todo, que é a pesquisa com dados orais de especialistas que tem alto grau de especialização, ou seja, não nos referimos aqui a especialistas que trabalham em aspectos mais culturais da pesquisa, mas sim, especialistas que tem escolaridade e um tempo razoável de atuação em contextos profissionais técnicos e tecnológicos.

Neste trabalho, trazemos algumas considerações acerca da problemática da variação terminológica, os modelos teóricos e metodológicos adotados para o tratamento dos dados, os dados selecionados bem como as discussões que são possíveis de serem feitas a partir de um estudo terminológico que considera esses elementos negligenciados.

\section{TERMINOLOGIA: MUDANÇA DE PARADIGMA}

A Terminologia, como uma das disciplinas do léxico, vem sofrendo um conjunto de modificações ao longo de sua existência como disciplina: quando sai de uma perspectiva puramente normativista para assentar-se em um conjunto de reflexões que convivem entre a normatização e a normalização, a disciplina se transforma ao longo dos anos e nascem inúmeras abordagens que problematizam os conceitos epistemológicos e metodológicos da disciplina. Dentre essas mudanças, o aceite ou não da variação e o status de que a pesquisa terminológica deve considerar diversos aspectos que vão além de textos escritos e contextos específicos são as que colocaremos em evidência neste estudo.

Quanto ao aspecto do aceite ou não da variação, essa é uma questão que existe na gênese da disciplina: Eugen Wüster e seu grupo de pesquisadores são considerados os primeiros pensadores da Terminologia moderna, entendida aqui como um campo teórico e metodológico que se ocupa da normatização. Nesse sentido, a variação era vista como um empecilho, algo que deveria ser evitado a todo o custo, em nome de uma norma inviolável e que ajudaria na comunicação em ambientes profissionais.

Por outro lado, no final da década de 90 , houve um grande interesse, por parte dos linguistas, pela linguagem em ambientes profissionais, sobretudo por conta do trabalho dos tradutores, com o avançar da tecnologia e com a popularização das ciências. A partir desse contexto, foi observada a ineficácia das ideias wusterianas, que, em muitos ambientes acadêmicos técnico-científicos, sobretudo no uso real, não se mantinham e se relegava um imenso material vivo e atualizado das linguagens especializadas. Nesse sentido, o trabalho dos linguistas foi chamar a atenção para esse aspecto do paradigma wusteriano e criar um novo paradigma que entendesse a variação como algo natural e necessário dentro do discurso técnico-científico. Cabré (2009, p. 10) avalia, sob o prisma da Linguística, que o pensamento wusteriano tinha "falta de adequação descritiva da separação entre terminologias e palavras. A vontade prescritiva como uma única meta da 
atividade terminológica; a ausência de observações sobre o aspecto fonético e sintático do léxico, sobre a diacronia, a oralidade, os registros funcionais etc. ${ }^{1 "}$.

A partir de sua análise sobre as ideias e sobre o que ficou conhecido como a Teoria Geral da Terminologia ${ }^{2}$, que era creditada a Wüster, Maria Teresa Cabré, filóloga e terminológa catalã, propõe uma teoria que aponta modos e perspectivas de análise das terminologias de diferentes áreas, diferentemente da teoria wusteriana, que partia da perspectiva mais restrita das ciências naturais e tecnológicas e que ele fazia crer que poderia ser aplicado em qualquer outro campo do saber humano. Cabré (2003), por seu turno, cria uma teoria que é mais ampla quando aceita a variação tanto denominativa quanto cognitiva como algo natural e necessário dentro dos discursos especializados. A teoria de Cabré ficou conhecida como Teoria Comunicativa da Terminologia. A partir dessa perspectiva, o papel do linguista não é mais evitar a variação, mas sim reconhecê-la como natural e observar os resultados de sua presença nos diferentes discursos especializados. Cabré (1999) inicia a publicação dos princípios de sua teoria na década de 90 e até hoje vem desenvolvendo reflexões, juntamente com os seus seguidores, sobre a variação terminológica, e esta se tornou uma das principais tônicas dos estudos terminológicos que ficaram conhecidos como descritivos, em contraposição aos estudos prescritivos feitos por Wüster e seus seguidores.

Dentre os estudos descritivistas de Cabré e de seus seguidores, a proposta elaborada por Freixa (2002) busca organizar as causas da variação denominativa e cognitiva da variação terminológica. Para Freixa (2002), as causas que motivam a variação no discurso especializado podem ser organizadas em seis grandes grupos, os quais ela denomina: causas prévias, dialetais, funcionais, discursivas, interlinguísticas e cognitivas. O quadro a seguir foi adaptado de Freixa (2014):

Quadro 1: Tipos e causas da variação denominativa, de acordo com Freixa (2002, 2014)

\begin{tabular}{|c|c|}
\hline TIPOS & CAUSAS \\
\hline Causas prévias & $\begin{array}{l}\text { Redundância linguística, arbitrariedade do signo } \\
\text { linguístico, possibilidade de variação nas línguas naturais }\end{array}$ \\
\hline Causas dialetais & Variação diatópica, cronológica e social \\
\hline $\begin{array}{c}\text { Causas } \\
\text { funcionais }\end{array}$ & $\begin{array}{c}\text { Adequações ao nível da língua e ao nível de } \\
\text { especialização }\end{array}$ \\
\hline $\begin{array}{c}\text { Causas } \\
\text { discursivas }\end{array}$ & $\begin{array}{c}\text { Evitar repetições, economia linguística, criatividade, } \\
\text { ênfase e expressividade }\end{array}$ \\
\hline
\end{tabular}

\footnotetext{
${ }^{1}$ Do original: la falta de adecuación descriptiva de la separación entre los términos y las palabras, la voluntad prescriptiva como única meta de la actividad terminológica, la ausencia de observación sobre los aspectos fonéticos y sintácticos del léxico, sobre la diacronía, la oralidad, los registros funcionales etc. (tradução nossa).

${ }^{2} \mathrm{O}$ que ficou conhecido como Teoria Geral da Terminologia ou TGT é um conjunto de princípios assentados na lógica e na normatização da linguagem propostos por Wüster e seu grupo de estudiosos em Viena. Embora Wüster não tenha proposto uma teoria, seus seguidores acabaram considerando o popularizando o termo. Essas ideias podem ser conhecidas no livro Introducción a la teoría general de la terminología y a la lexicografía terminológica (WUSTER, 1998).
} 


\begin{tabular}{|c|c|}
\hline $\begin{array}{c}\text { Causas } \\
\text { interlinguísticas }\end{array}$ & $\begin{array}{c}\text { Convivência entre termos de línguas diferentes e } \\
\text { oriundos de grupos de pesquisa de países e continentes } \\
\text { diferentes }\end{array}$ \\
\hline $\begin{array}{c}\text { Causas } \\
\text { cognitivas }\end{array}$ & $\begin{array}{c}\text { Imprecisão conceitual, distância ideológica e diferença de } \\
\text { conceptualização }\end{array}$ \\
\hline
\end{tabular}

Fonte: Freixa (2014, p. 323)

Muito embora a autora organize as causas em blocos, Freixa (2013) reconhece que as causas da variação não atuam independentemente e nem por blocos, porque, para ela, muitas dessas causas trabalham coordenadas e podem influenciar a variação denominativa de um discurso especializado.

Dentre os tipos e causas da variação denominativa, nos interessaremos pelas causas funcionais e discursivas da variação terminológica porque ela mostra como a variação se apresenta em aspectos que são pragmáticos e discursivos, aspectos que distinguem abordagens normativa e descritiva da Terminologia: enquanto que a abordagem prescritiva não se interessa por esses aspectos, a abordagem descritivista os coloca em evidência para flagrar um uso real das terminologias de uma área.

$\mathrm{Na}$ perspectiva da Terminologia descritiva, variação funcional está relacionada a aspectos discursivos e pragmáticos, ou seja, da relação entre o especialista e outros indivíduos com os quais esse especialista se comunica em diferentes contextos em que o discurso especializado pode ser encontrado em nossa sociedade. Outro aspecto dessa comunicação é o canal comunicativo utilizado pelo especialista: se o especialista se utiliza da oralidade ou da escrita para apresentar seu conhecimento a outros especialistas ou leigos pode causar variação denominativa, visto que o especialista precisa adaptar seu discurso aos diferentes membros da sua audiência. $O$ uso de uma das formas de materialização da linguagem obriga a Terminologia a pensar na oralidade, que foi completamente negligenciada pela abordagem prescritiva da Terminologia.

Quando a Terminologia considera os aspectos funcionais da variação terminológica, se vê obrigada a considerar a oralidade e a escrita como elementos causadores dessa variação. A partir disso, é possível afirmar que a própria materialização e a densidade lexical de uma ou da outra forma da linguagem acabam causando a variação. Além disso, o próprio gênero textual utilizado, se da escrita ou da oralidade, é um fator motivador para que o especialista possa adaptar seu discurso às condições de produção do discurso especializado por parte do especialista. Nesse mesmo sentido, é importante salientar que a adaptação do discurso do especialista a sua audiência também é causa relevante: em outras palavras, se um especialista fala ou escreve a um grupo de outros especialistas com a mesma formação acadêmica ou que ocupem o mesmo lugar dentro do espectro do conjunto de especialistas em uma área, ele vai adaptar seu discurso a essa circunstância, o que leva ao uso de uma forma específica e mais técnica do discurso especializado de seu campo; por outro lado, se ele se comunica, por meio da oralidade ou da escrita, com especialistas com menor grau de especialização ou experiência, bem como com um grupo de leigos, o especialista precisa adaptar seu discurso a essa circunstância comunicativa usando a variedade mais popular do seu discurso especializado. Nos dois 
casos, é possível observar a variação denominativa como um aspecto fundamental para o sucesso comunicativo nessa circunstância.

Cumpre considerar que os estudos em Terminologia ainda não apresentaram uma preocupação importante quanto a esse aspecto, visto que a oralidade em Terminologia é mais comumente trabalhada em estudos que buscam a terminologia utilizada por especialistas com baixo grau de escolaridade ou que não têm textos escritos como instrumento de comunicação. Nesses estudos, aspectos da própria oralidade para além da materialização de um corpus não são considerados, o que deixa uma lacuna importante na descrição das terminologias utilizadas pelos especialistas. É importante ressaltar também que, de acordo com Seghezzi (2011), isso não é uma exclusividade dos estudos feitos em língua portuguesa.

\section{METODOLOGIA}

Os dados extraídos deste estudo são um resumo dos dados de Serra (2019), em que apresentamos um conjunto de dados mais amplo para a análise, um total de 139.869 palavras ou tokens. No entanto, para este estudo, selecionamos uma amostra de 62.666 palavras (tokens) que foram retiradas de textos especializados em diferentes gêneros textuais. O Quadro 2, a seguir, mostra como está distribuído o corpus utilizado neste estudo.

Quadro 2: Quantidade de palavras em ambos os corpora

\begin{tabular}{|c|c|c|}
\hline MATERIALIZAÇÃO & GÊNERO & $\begin{array}{c}\text { QUANTIDADE DE } \\
\text { PALAVRAS }\end{array}$ \\
\hline \multirow{4}{*}{ ORALIDADE } & Palestra & 12.175 \\
\cline { 2 - 3 } & Aula & 10.642 \\
\cline { 2 - 3 } & $\begin{array}{c}\text { Entrevista em } \\
\text { Programa de } \\
\text { Televisão }\end{array}$ & 9.742 \\
\hline \multirow{2}{*}{ ESCRITA } & Artigo Científico & 10.708 \\
\cline { 2 - 3 } & Apostila & 9.224 \\
\cline { 2 - 3 } & Artigo de & 10.175 \\
\hline DOTALulgação & \multicolumn{2}{|c}{62.666} \\
\hline
\end{tabular}

Fonte: Serra (2019)

Como se observa, a média de palavras por grupo de gêneros textuais é de 10 mil palavras. Esse total foi fixado para que houvesse uma semelhança no grupo dos textos e para que o fator quantidade de palavras não interferisse nos resultados alcançados por meio da comparação que foi feita para observar a quantidade de variação em cada gênero especializado, sobretudo porque este estudo busca observar a importância que a oralidade tem dentro dos fatores que condicionam a variação denominativa encontrada em um corpus constituído por textos especializados orais e escritos. 
Para a comparação, foram selecionados 20 conceitos que poderiam ser encontrados em todos os textos selecionados. Para o estudo, foram selecionados apenas textos que tratassem a plantação da cana-de-açúcar e seus subtemas, como morfologia da planta, solo, irrigação, tecnologia de plantio, entre outros subtemas pertinentes. Como havia muitos conceitos que não eram possíveis de serem detectados em todos os textos, para fazer a comparação entre esses textos, foi necessário encontrar aqueles que poderiam ser encontrados em todos e observar como os diferentes especialistas denominavam aqueles conceitos em circunstâncias diferentes. O Quadro 3, a seguir, traz os 20 conceitos selecionados de um conjunto de conceitos do campo conceitual plantação, no universo da cana-de-açúcar:

Quadro 3: Os conceitos analisados

\begin{tabular}{|c|c|c|}
\hline SUBTEMA & CONCEITOS & CÓDIGO \\
\hline $\begin{array}{l}\text { Morfologia da } \\
\text { planta }\end{array}$ & Caule da planta de cana-de-açúcar & CA1 \\
\hline $\begin{array}{l}\text { Morfologia da } \\
\text { planta }\end{array}$ & Espécie de cana-de-açúcar que foi modificada ou clonada & $\mathrm{CB} 2$ \\
\hline $\begin{array}{l}\text { Morfologia da } \\
\text { planta }\end{array}$ & Broto de cana-de-açúcar ou colmo formado após o corte & CC3 \\
\hline $\begin{array}{l}\text { Morfologia da } \\
\text { planta }\end{array}$ & $\begin{array}{l}\text { Processo de desenvolvimento de novos brotos de cana-de- } \\
\text { açúcar na touceira }\end{array}$ & CD4 \\
\hline $\begin{array}{l}\text { Morfologia da } \\
\text { planta }\end{array}$ & Conjunto de raízes e de colmos da cana-de-açúcar & CE5 \\
\hline Plantio & $\begin{array}{l}\text { Planta da família das gramíneas, de que se extrai caldo } \\
\text { açucarado para a produção de açúcar, bebida alcoólica, } \\
\text { combustível e outros bens de consumo popular }\end{array}$ & CF6 \\
\hline Plantio & Terreno onde é plantada a cana-de-açúcar & CG7 \\
\hline Plantio & Espaço no canavial entre as fileiras de cana-de-açúcar & $\mathrm{CH} 8$ \\
\hline Plantio & Conjunto de touceiras de cana-de-açúcar plantadas em fila & CI9 \\
\hline Plantio & Processo de formação de brotos na cana-de-açúcar & CJ10 \\
\hline Plantio & Conjunto de prática do plantio de cana-de-açúcar & CK11 \\
\hline Plantio & $\begin{array}{l}\text { Conjunto de práticas necessárias para o desenvolvimento } \\
\text { da planta de cana-de-açúcar }\end{array}$ & CL12 \\
\hline Plantio & $\begin{array}{c}\text { Planta de cana-de-açúcar que se desenvolve após o } \\
\text { corte/colheita }\end{array}$ & CM13 \\
\hline Plantio & $\begin{array}{l}\text { Conjunto de técnicas de cuidados do solo para o plantio } \\
\text { de cana-de-açúcar }\end{array}$ & CN14 \\
\hline Plantio & $\begin{array}{l}\text { Tipo de cana-de-açúcar que chega ao pico de } \\
\text { desenvolvimento vegetal em } 12 \text { meses }\end{array}$ & CO15 \\
\hline Plantio & $\begin{array}{l}\text { Matéria orgânica que sobra da cana-de-açúcar após o } \\
\text { processo de produção industrial e a quantidade de massa } \\
\text { física de uma planta de cana-de-açúcar }\end{array}$ & CP16 \\
\hline
\end{tabular}




\begin{tabular}{|c|c|c|}
\hline Plantio & $\begin{array}{c}\text { Restos de folha de cana-de-açúcar que caem no canavial e } \\
\text { servem para a proteção do solo e para a produção de } \\
\text { energia elétrica em usinas termoelétricas }\end{array}$ & CQ17 \\
\hline Plantio & $\begin{array}{c}\text { Seleção de variedades de cana-de-açúcar de acordo com } \\
\text { suas qualidades biológicas }\end{array}$ & CR18 \\
\hline Plantio & $\begin{array}{c}\text { Cavidade alongada feita no canavial para a produção de } \\
\text { linha de cana-de-açúcar }\end{array}$ & CS19 \\
\hline Praga & $\begin{array}{c}\text { Praga da cana-de-açúcar que consome a seiva e as fibras } \\
\text { da cana-de-açúcar }\end{array}$ & CT20 \\
\hline
\end{tabular}

Fonte: Serra (2019)

Após a seleção dos conceitos, no corpus, com a ajuda do programa computacional AntConc ${ }^{3}$, foi possível encontrar as denominações de todos os 20 conceitos nos diferentes gêneros textuais selecionados para o estudo. Em outras palavras, em cada conjunto de palavras (tokens) foi feito uma busca com o programa e encontradas diferentes denominações para os 20 conceitos, que serão apresentadas a seguir.

Após chegar aos resultados das denominações encontradas, utilizamos o índice de variação denominativa a fim de observar qual o gênero textual ou em que tipo de materialização do texto é possível encontrar maior variação denominativa. O índice de variação denominativa foi usado por Freixa (2002) para fazer comparação das quantidades de variação em um conjunto de textos diferentes. A técnica consiste em um cálculo da razão simples entre o número de conceitos e o número de denominação. Isso foi feito em todos os conjuntos e os resultados dessa comparação apresentaremos na seção seguinte.

\section{A VARIAÇÃO DENOMINATIVA NO DISCURSO ESPECIALIZADO DO UNIVERSO DA CANA-DE-AÇÚCAR: A ORALIDADE E A ESCRITA}

Considerando as diferentes rodadas feitas no AntConc para encontrar as diferentes denominações utilizadas pelos especialistas, criamos o Quadro 4, a seguir, que mostra as diferentes denominações utilizadas pelos especialistas em cana-de-açúcar no universo da cana-de-açúcar em diferentes contextos de produção desses textos especializados. O quadro é uma síntese de todos os resultados encontrados, que, por conta de espaço, não será possível apresentar todos os resultados separadamente. O Quadro 5, que será apresentado mais à frente, busca mostrar esses dados com maior detalhe, ao menos, numericamente.

O Quadro 4, por sua vez, mostra que a variação é bastante substancial no corpus que foi selecionado para a pesquisa, visto que todos os conceitos selecionados e encontrados em todos os conjuntos de textos apresentam ao menos mais de duas denominações, o

\footnotetext{
${ }^{3} \mathrm{O}$ software AntConc é um processador de textos que se popularizou nas pesquisas dos estudos lexicais por conta de sua facilidade e por ser gratuito. Ele pode ser baixado gratuitamente na página do professor Laurence Antony, da Universidade de Waseda, Japão.
} 


\section{das Letras}

que indica que grande parte dos dados é polidenominativa, ou seja, tem mais de uma denominação.

Quadro 4: A variação denominativa encontrada no corpus

\begin{tabular}{|c|c|c|}
\hline CÓDIGO & TERMO & VARIANTE \\
\hline CA1 & Colmo & $\begin{array}{c}\text { Colmo da cana-de-açúcar, colmo da cana, caule, colmo } \\
\text { da planta, haste, caules da cana-de-açúcar, talo, colmo } \\
\text { de cana }\end{array}$ \\
\hline $\mathrm{CB} 2$ & Cultivar & $\begin{array}{c}\text { Variedade, clone, cultivar de cana-de-açúcar, variedade } \\
\text { da cultura da cana-de-açúcar, variedade de cana-de- } \\
\text { açúcar, variedade de cana, cana que foi geneticamente } \\
\text { modificada }\end{array}$ \\
\hline CC3 & Perfilho & $\begin{array}{l}\text { Broto, perfilho da cana-de-açúcar, perfilhos de cana, } \\
\text { colmo secundário }\end{array}$ \\
\hline $\mathrm{CD} 4$ & Perfilhamento & $\begin{array}{l}\text { Perfilhamento da cana-de-açúcar, desenvolvimento do } \\
\text { colmo }\end{array}$ \\
\hline CE5 & Soqueira & \\
\hline CF6 & $\begin{array}{l}\text { Cana-de- } \\
\text { açúcar }\end{array}$ & $\begin{array}{l}\text { Cana, planta, variedade, variedade de cana, variedade } \\
\text { de cana-de-açúcar, planta de cana-de-açúcar, planta de } \\
\text { cana, planta da cana-de-açúcar, cultura, pé de cana }\end{array}$ \\
\hline CG7 & Canavial & $\begin{array}{l}\text { Terreno, terra, área com cana, área cultivada, área de } \\
\text { cana-de-açúcar, área de cultivo, área de plantio, área } \\
\text { plantada, área colhida, área, canteiro, canteiro de cana, } \\
\text { plantação, terra, área de cana, talhão, terreno cultivado, } \\
\text { área de cana, área plantada com cana, área canavieira, } \\
\text { área de cultivo de cana-de-açúcar, plantação de cana, } \\
\text { plantação }\end{array}$ \\
\hline CI8 & Entrelinha & $\begin{array}{c}\text { Entrelinhas de plantio, espaçamento, espaçamento } \\
\text { entre sulcos, espaçamento no plantio, entre fileiras, } \\
\text { distância entre fileiras, espaçamento entre sulcos, } \\
\text { entrelinha da cultura, espaçamento da cana-de-açúcar, } \\
\text { espaçamento entre canais, rua, espaçamento da } \\
\text { entrelinha, faixa de espaçamento, espaçamento da } \\
\text { cultura }\end{array}$ \\
\hline CI9 & Linha & $\begin{array}{c}\text { Linhas da cultura de cana-de-açúcar, linha de planta, } \\
\text { linha de cana, linha de plantio, fileiras, fileiras de } \\
\text { planta, leira }\end{array}$ \\
\hline CJ10 & Brotação & $\begin{array}{c}\text { Brotação das soqueiras, emergência da cana-de-açúcar, } \\
\text { brota, emergência da cana, brotação das soqueiras, } \\
\text { brotação da soca, brotação da socaria, brotação das } \\
\text { gemas }\end{array}$ \\
\hline CK11 & Cultura & $\begin{array}{l}\text { Cultura da cana, cultura da cana-de-açúcar, cultura } \\
\text { agrícola da cana, cultura da cana, cultura de cana, }\end{array}$ \\
\hline
\end{tabular}




\section{das Letras}

\begin{tabular}{|c|c|c|}
\hline & & $\begin{array}{c}\text { cultura de cana-de-açúcar, cultura canavieira, cultivo de } \\
\text { cana, cultivar da cana-de-açúcar, cultura de cana, } \\
\text { cultivo da cana }\end{array}$ \\
\hline CL12 & Plantio & $\begin{array}{l}\text { Plantio da cana, plantio da cana-de-açúcar, plantio de } \\
\text { cana, plantio do canavial, cultivo da cana, cultivo da } \\
\text { cana-de-açúcar, cultivo, plantio de canavial, plantio de } \\
\text { muda, plantio da cana-de-açúcar }\end{array}$ \\
\hline CM13 & Cana-soca & $\begin{array}{c}\text { Cana soca, soca, rebrota da soqueira, rebrota, soqueira, } \\
\text { soca }\end{array}$ \\
\hline CN14 & $\begin{array}{l}\text { Preparo do } \\
\text { solo }\end{array}$ & $\begin{array}{c}\text { Preparo, preparação do solo, manejo do solo, preparo } \\
\text { de solo, preparo do terreno, ajuste do solo }\end{array}$ \\
\hline CO15 & Cana-ano & $\begin{array}{c}\text { Cultura de doze meses, cana de ano, cana-de-ano, } \\
\text { plantio-de-ano, cana-de-ano, plantio de ano, cana de } 12 \\
\text { meses }\end{array}$ \\
\hline CP16 & Biomassa & Fitomassa, biomassa da cana \\
\hline CQ17 & Palha & $\begin{array}{l}\text { Palha de cana-de-açúcar, palha da cana, palha de cana- } \\
\text { de-açúcar, folha seca, palhada, palha da cana-de-açúcar, } \\
\text { palha da cana }\end{array}$ \\
\hline CR18 & $\begin{array}{l}\text { Manejo } \\
\text { varietal }\end{array}$ & $\begin{array}{c}\text { Manejo da cultura, manejo de variedades, manejo, } \\
\text { manejo varietal da cana, manejo cultural }\end{array}$ \\
\hline CS19 & Sulco & Sulco de plantio, fileira \\
\hline CT20 & Broca & roca da cana-de-açúcar, broca de cana, broca da cana \\
\hline
\end{tabular}

Fonte: Serra (2019)

Como observamos no Quadro 4, todos os conceitos apresentados mostram que nessa terminologia o fenômeno da variação denominativa é bastante comum, o que lança a hipótese de que ela tenha uma funcionalidade nesse discurso. Com a variação denominativa constatada, buscamos encontrar a motivação dessa variação a esses conceitos, considerando os diferentes contextos ou condições de produção do texto, ou seja, os diferentes gêneros indicam diferentes contextos, visto que os gêneros foram selecionados considerando que todos são especializados, mas que têm níveis de especialização diferentes, visto que gêneros como artigo científico e palestras pertencem a contextos comunicativos altamente especializados, em oposição a gêneros como aula e apostila, que têm um aspecto mais didático, e, portanto, destinados a semileigos ou especialistas em formação, ou o artigo de divulgação e entrevistas de televisão, destinados ao público-leigo. Considerando os diferentes contextos, organizamos os resultados dos índices de variação denominativa a partir dos gêneros no Quadro 5, a seguir.

Quadro 5: Índices de variação denominativa dos dados

\begin{tabular}{|c|c|c|c|c|c|}
\hline CANAL & GÊNERO & CONCEITOS & DENOMINAÇÕES & ÍNDICES & M \\
\hline \multirow{2}{*}{ Oralidade } & Palestra & 20 & 42 & 2,1 & \multirow{2}{*}{2,0} \\
\cline { 2 - 6 } & Aula & 20 & 38 & 1,9 & \\
\hline
\end{tabular}




\begin{tabular}{|c|c|c|c|c|c|}
\hline & Entrevista & 20 & 41 & 2,0 & \\
\hline \multirow{4}{*}{ Escrita } & $\begin{array}{c}\text { Artigo } \\
\text { Científico }\end{array}$ & 20 & 48 & 2,4 & \\
\cline { 2 - 6 } & Apostila & 20 & 50 & 2,5 & \multirow{2}{*}{2,3} \\
\cline { 2 - 6 } & $\begin{array}{c}\text { Artigo de } \\
\text { Divulgação }\end{array}$ & 20 & 43 & 2,1 & \\
\hline
\end{tabular}

Fonte: Serra (2019)

Esses dados mostram que a variação denominativa é maior nos gêneros da escrita do que nos gêneros orais. Os índices mostram que, na escrita, os conceitos recebem maior número de denominação do que na oralidade. É importante considerar, no entanto, as diferentes variáveis por trás desses resultados, e alguns aspectos particulares dos diferentes gêneros, visto que os resultados não são tão homogêneos como nos faz entender uma leitura mais ampla dos resultados. Como é possível observar no quadro, alguns índices são muito próximos ou iguais em diferentes textos, mostrando que, mesmo em diferentes contextos, o fenômeno da variação denominativa está relacionado a diferentes aspectos que não são puramente a materialização do canal.

A título de ilustração, destacamos os gêneros palestras e artigo de divulgação, que, estando em contextos opostos em uma escala imaginária de contextos especializados, apresentam os mesmos índices de variação. Obviamente que os resultados apresentados no quadro não deixam de ser uma generalização, isto é, alguns conceitos podem apresentar maior variação do que outros e isso não se dá do mesmo modo nos dois contextos, isto é, alguns conceitos podem apresentar maior número de variação do que o outro em um contexto e o mesmo conceito pode apresentar menor número de variação em outro contexto, o número dessa variante pode ser equiparável a partir de outro conceito que varia mais nesse contexto. $O$ fato é que gêneros que são utilizados no mesmo contexto apresentam índices de variação diferentes, mostrando que a materialização parece ser um fator relevante nesses índices diferentes. Por exemplo, no contexto mais especializado, o artigo científico representaria a escrita e a palestra a oralidade. O primeiro apresenta índice de variação denominativa maior $(2,4)$ do que o segundo $(2,1)$. Embora seja em décimos essa diferença, é importante atentar que estamos tratando de uma razão simples, o que mostra que esse índice é puxado por uma diferença entre as díspares quantidades de denominações atribuídas aos conceitos.

De qualquer modo, considerando esses resultados, é importante atentar para o fato de que textos que têm quantidade de palavras (tokens) próximas ou semelhantes apresentam índices diferentes, mesmo quando estamos trabalhando com os mesmos conceitos. Esse resultado aponta para um fator que parece ser mais relevante do que esses fatores analisados. Uma hipótese pode ser a materialização (oralidade e escrita), visto que, de um modo geral, a escrita apresentou maior índice de variação, e os índices de variação denominativa nesse grupo, em todos os gêneros, apresentam-se maiores. A hipótese se firma no que afirma Koch (2015), quando diz que o texto oral é menos denso, lexicalmente falando, do que o texto escrito. Enquanto que o texto escrito se apoia na descrição dos elementos, o texto oral é mais contextualizado, visto que muito da 
compreensão de um enunciado pode ser feita por meio do contexto em que acontece o discurso.

Esse aspecto do canal dialoga com os resultados dessa amostra, visto que, mesmo com o mesmo número de palavras ou com o número de palavras próximo, a escrita mostra-se muito mais variável do que a oralidade. Lembramos que, nos contextos de oralidade, temos muito mais elementos que colaboram para uma menor densidade lexical, ou seja, nesse contexto, o especialista conta com datashow, elementos pictóricos e gestos para indicar um elemento, e a repetição é menos condenável do que na escrita. Esses elementos apontam para o fato de que há menor necessidade de denominar os conceitos do que na escrita, o que, a nosso ver, justificaria a diferença entre os resultados apresentados na comparação entre os dois gêneros.

Com isso, entendemos a importância de se considerar, nas pesquisas terminológicas, dados da oralidade, visto que ainda são poucos os estudos terminológicos que se ocupam do texto oral produzido por especialistas em diferentes contextos especializados, no diálogo com diferentes púbicos. Os resultados mostram que os textos orais apresentam menor variação por conta de seu próprio contexto, e esses elementos devem ser considerados como elementos importantes para a análise linguística dos discursos especializados. Entender como funciona esse contínuo, oralidade e escrita, e como ele opera na variação terminológica também deve ser uma das preocupações dos estudos em Terminologia para que possamos ter uma análise mais ampla do discurso especializado.

\section{CONSIDERAÇÕES FINAIS}

A pesquisa mostrou que a variação denominativa é uma realidade no discurso especializado do universo da cana-de-açúcar. Esses resultados mostram também a importância de se considerar a oralidade e a escrita como fatores dessa variação. Os modelos teóricos adotados no estudo mostram que a variação tem muitos aspectos e que esses aspectos devem ser considerados na pesquisa terminológica, sob pena de se deixar de fazer uma descrição mais fiel e completa dos universos especializados.

Este texto chama a atenção das pesquisas feitas em Terminologia no Brasil para considerar a oralidade não apenas de indivíduos com baixo grau de escolaridade, como é mais comum, mas também as pesquisas da oralidade de especialistas com alto grau de especialização e que também se utilizem de textos escritos em sua comunicação no papel de especialista de um determinado campo do saber. Estudos semelhantes já acontecem dentro dos estudos linguísticos variacionistas, a exemplo, o projeto NURC, que busca descrever a linguagem culta falada no Brasil. Esses projetos e estudos podem servir de algum modo de modelo para os estudos terminológicos avançar em sua descrição dessa oralidade. Por fim, vale lembrar que o campo descritivo da Terminologia também se diferencia da abordagem normativista a partir da aceitação da oralidade especializada como um objeto de estudos, visto que a abordagem tradicional busca sua análise em textos predominantemente escritos. 


\section{REFERÊNCIAS}

CABRÉ, Maria Teresa. La terminologia: representación y comunicación: elementos para una teoría de base comunicativa y outros artículos. Barcelona: Institut Universitari de Lingüística Aplicada, 1999.

. La teoria comunicativa de la terminología: una aproximación lingüística a los términos. Revue Francaise de Linguistique Apliquée, v. 2, p. 9-15, 2009.

. Theories of terminology: their descriptions, prescriptions and explanation. Terminology, n. 9, v. 2, p. 63-199, 2003.

FREIXA, Judith. La variación denominativa en terminología: tipos y causas. In. ISQUERDO, Aparecida Negri; DAL CORNO, Giselle Olivia Montovani (Orgs.). As ciências do léxico: lexicologia, lexicografia e terminologia. v. 7. Campo Grande: EDUFSM, 2014, p. 312-330.

.Otra vez sobre las causas de la variación denominativa. Revista Debate Terminológico. n. 9, v. 1, p. 11-37, 2013.

$\mathrm{KOCH}$, Ingedore Villaça. Introdução à linguistica textual: trajetória e grandes temas. $2^{\mathrm{a}}$ ed. São Paulo: Contexto, 2015.

SEGHEZZI, Natália. Variación terminológica y canal de comunicación: estudios contrastivos de textos especializados escritos y orales sobre lingüística. 342f. Tese (Doutorado em Lingüística), Institut Universitari de Lingüística Aplicada, Universitat Pompeu Fabra, 2011.

SERRA, Luís Henrique. A variação denominativa no discurso especializado da cana-de-açúcar no Brasil: uma pesquisa sobre a variaģão funcional. 155fls. Tese (Doutoramento em Letras Filologia e Língua Portuguesa), Programa de Pós-Graduação em Filologia e Língua Portuguesa, Universidade de São Paulo, 2019.

WÜSTER, Eugen. Introducción a la teoría general de la terminología y a la lexicografía terminológica. Tradução de Anne-Cécile Nokerman. Barcelona: IULA, 1998.

Recebido em: 28/02/2019

Aprovado em: 07/06/2019

Publicado em: 28/09/2019 